\title{
Unique genetic profile of sporadic colorectal cancer liver metastasis versus primary tumors as defined by high-density single-nucleotide polymorphism arrays
}

Luís Muñoz-Bellvis ${ }^{1}$, Celia Fontanillo², María González-González ${ }^{3}$, Eva Garcia ${ }^{4}$, Manuel Iglesias ${ }^{1}$, Carmen Esteban ${ }^{1}, \mathrm{ML}$ Gutierrez ${ }^{3}, \mathrm{MM} \mathrm{Abad}^{5}$, Oscar Bengoechea $^{5}$, Javier De Las Rivas², Alberto Orfao ${ }^{3,6}$ and JM Sayagués ${ }^{3,6}$

${ }^{1}$ Unidad de Cirugía Hepatobiliopancreática, Departamento de Cirugía, Hospital Universitario de Salamanca, Salamanca, Spain; ${ }^{2}$ Grupo de Investigación en Bioinformática y Genómica Funcional, Centro de Investigación del Cáncer (IBMCC-CSIC/USAL), Universidad de Salamanca, Salamanca, Spain; ${ }^{3}$ Servicio General de Citometría, Departamento de Medicina and Centro de Investigación del Cáncer (IBMCC-CSIC/ USAL), Universidad de Salamanca, Salamanca, Spain; ${ }^{4}$ Unidad de Genómica y Proteómica, Centro de Investigación del Cáncer (IBMCC-CSIC/USAL), Universidad de Salamanca, Salamanca, Spain and ${ }^{5}$ Departamento de Patología, Hospital Universitario de Salamanca, Salamanca, Spain

Most genetic studies in colorectal carcinomas have focused on those abnormalities that are acquired by primary tumors, particularly in the transition from adenoma to carcinoma, whereas few studies have compared the genetic abnormalities of primary versus paired metastatic samples. In this study, we used high-density $500 \mathrm{~K}$ single-nucleotide polymorphism arrays to map the overall genetic changes present in liver metastases $(n=20)$ from untreated colorectal carcinoma patients studied at diagnosis versus their paired primary tumors $(n=20)$. MLH1, MSH2 and MSH6 gene expression was measured in parallel by immunohistochemistry. Overall, metastatic tumors systematically contained those genetic abnormalities observed in the primary tumor sample from the same subject. However, liver metastases from many cases (up to 8 out of 20) showed acquisition of genetic aberrations that were not found in their paired primary tumors. These new metastatic aberrations mainly consisted of (1) an increased frequency of genetic lesions of chromosomes that have been associated with metastatic colorectal carcinoma (1p, 7p, 8q, 13q, 17p, 18q, 20q) and, more interestingly, (2) acquisition of new chromosomal abnormalities (eg, losses of chromosomes 4 and $10 q$ and gains of chromosomes $5 p$ and $6 p$ ). These genetic changes acquired by metastatic tumors may be associated with either the metastatic process and/or adaption of metastatic cells to the liver microenvironment. Further studies in larger series of patients are necessary to dissect the specific role of each of the altered genes and chromosomal regions in the metastatic spread of colorectal tumors.

Modern Pathology (2012) 25, 590-601; doi:10.1038/modpathol.2011.195; published online 6 January 2012

Keywords: colorectal cancer; copy number change; FISH; liver metastases; SNP array

Correspondence: Professor A Orfao, MD, PhD, Centro de Investigación del Cancer, Paseo de la Universidad de Coimbra S/N, 37007 Salamanca, Spain.

E-mail: orfao@usal.es

${ }^{6}$ These authors contributed equally to this work and should be considered as senior last authors.

Received 3 August 2011; revised 17 October 2011; accepted 17 October 2011; published online 6 January 2012
Occurrence of distant metastasis in sporadic colorectal cancer (eg, liver metastasis) confers a poor prognosis. In fact, metastatic disease is the main cause of death in colorectal carcinoma patients, and the liver is the most common site for metastatic spread of colorectal carcinoma. ${ }^{1,2}$ Current knowledge about the genetic pathways of clonal evolution 
in colorectal carcinoma suggest that development of colorectal cancer could be triggered by the clonal expansion of cells that carry mutations, which most frequently involve the APC, RAS, TP53 and/or DCC genes, and lead to a growth and/or survival advantage of tumor cells. ${ }^{3}$ As metastatic cells derive from primary tumor cells, specific genomic alterations driving these ultimate steps of the metastatic cascade are expected to be acquired over the genomic profile of neoplastic cells from the primary tumor. ${ }^{4}$ The genomic abnormalities, which are potentially characteristic of such advanced stages of the disease, are complex and so far, poorly described and partially understood. This relates to the fact that most genetic studies in colorectal cancer have focused on those abnormalities that are acquired in primary tumors, particularly, in the transition from adenoma to carcinoma, and few studies have compared these abnormalities with those observed in paired metastatic samples. ${ }^{5-7}$ Despite this, multiple recurrent chromosomal abnormalities, which are found in primary tumors have been associated with metastatic colorectal carcinoma. Among others, these mainly include numerical changes such as gains of chromosomes $8 q, 13 q$ and $20 q$, and losses of the $1 p, 8 p, 17 p$ and 18q chromosomal regions. ${ }^{8-10}$ However, the molecular mechanisms underlying the association of such genetic profiles with metastatic colorectal carcinoma remain largely unknown.

Previous studies using conventional karyotyping, ${ }^{5}$ comparative genomic hybridization (CGH), ${ }^{5,7,11}$ fluorescence in situ hybridization (FISH) ${ }^{9,11}$ or microsatellite markers to detect regions of loss of heterozygosity (LOH), ${ }^{12}$ have largely failed in identifying recurrent chromosomal abnormalities acquired in metastatic versus primary colorectal tumors. This could be explained, at least in part, because of the relatively limited resolution of these techniques. More recently, the availability of highdensity single-nucleotide polymorphism (SNP) arrays has facilitated the identification of small regions of chromosomal gains and losses because of its higher resolution (down to $2.5 \mathrm{~kb}$ ), ${ }^{13}$ and provides new opportunities in the identification of novel cancer genes involved in the metastatic process of colorectal cancer. However, previous reports in which high-density SNP arrays have been used to investigate the genetic profiles of colorectal carcinoma have specifically focused on primary tumor samples, ${ }^{14}$ and to the best of our knowledge, no study has been reported so far in which highdensity SNP arrays are employed to investigate the potential genetic differences between paired primary and metastatic tumors from colorectal carcinoma patients.

In the present study, we applied high-density (500 K) SNP mapping arrays-mean distance between the interrogated SNPs of $5.8 \mathrm{~kb}$ (median intermarker distance of $2.5 \mathrm{~kb}$ ) - to map the overall genetic changes present in liver metastases from 20 untreated colorectal carcinoma patients studied at diagnosis versus their paired primary tumors $(n=40$ samples). Our goal was to search for recurrent genetic differences between paired primary versus metastatic tumor samples that might contain candidate genes highly characteristic of metastatic liver disease.

\section{Patients and methods}

\section{Patients and Samples}

Tissue specimens from 20 sporadic colorectal adenocarcinomas and 20 paired liver metastases ( $n=40$ samples) were obtained from 20 patients (13 males and 7 females; median age of 70 years, ranging from 49 to 80 years) after informed consent had been given by each subject. It should be noted that only patients with metastatic lesions able to be resected were included in this cohort, which, therefore, is not representative of the whole colorectal cancer patient population. All patients underwent surgical resection of both tumor tissues at the Department of Surgery of the University Hospital of Salamanca (Salamanca, Spain). All tumors were diagnosed and classified according to the WHO criteria, ${ }^{15}$ and they were all studied before any treatment was given. According to the tumor grade, 11 cases were classified as well-differentiated tumors, 8 as moderately- and one as poorly differentiated carcinomas. In all cases, histopathological grade was confirmed in a second independent evaluation by an experienced pathologist. Median follow-up at the moment of closing the study was of 37 months (range: 36-96 months). The study was approved by the local ethics committee of the University Hospital of Salamanca (Salamanca, Spain).

Seven primary tumors were localized in the rectum, and the other 13 were localized either in the right (cecum, ascending or transverse) or the left (descending and sigmoid) colon. The mean size of the primary tumors was of $5.3 \pm 1.9 \mathrm{~cm}$ with the following distribution according to their TNM stage at diagnosis: ${ }^{16}$ T3N0M0, two cases; T3N1M1, four cases; T3N1M0, four cases; T3N2M1, four cases; T4N0M1, one case; T4N0M0, three cases; T4N1M1, one case and; T4N2M1, one case. Liver metastases were identified either at the time of colorectal surgery $(n=11)$ or during the first year after initial diagnosis $(n=9)$; to date, patients have not shown any other metastasis. The mean size of the liver metastases was of $4.3 \pm 2.2 \mathrm{~cm}$.

After histopathological diagnosis was established, part of the primary tumor and its paired liver metastasis (both corresponding to a macroscopically tumoral region) were used to prepare single-cell suspensions. Once prepared, single-cell suspensions were resuspended in methanol/acetic acid (3/1; vol/vol) and stored at $-20^{\circ} \mathrm{C}$ for further interphase FISH analyses, as recently described. ${ }^{17}$ The remaining tissue was either fixed in formalin 
and embedded in paraffin, or frozen in liquid nitrogen and stored at room temperature or at $-80^{\circ} \mathrm{C}$, respectively. All tissues were evaluated after hematoxylin-eosin staining to confirm the presence of tumor cells and to evaluate their quantity in each individual sample. For SNP array studies, tumor DNA was extracted from representative areas of freshly frozen tumor tissues (primary tumors and liver metastases), which contained $\geq 65 \%$ epithelial tumor cells, localized mirror-cut to those used for iFISH analyses. In turn, normal DNA was extracted from peripheral blood leukocytes from the same patient. For the three types of samples (primary tumors, paired liver metastases and peripheral blood leukocytes), DNA was extracted using the QIAamp DNA mini kit (Qiagen, Hilden, Germany) following the instructions of the manufacturer.

\section{SNP Array Studies}

Each DNA sample derived from primary tumors and liver metastases and normal peripheral blood leukocytes was hybridized to two different $250 \mathrm{~K}$ Affymetrix SNP Mapping arrays (NspI and StyI SNP arrays, Affymetrix, Santa Clara, CA, USA); for this purpose, $250 \mathrm{ng}$ of DNA per array was used, according to the instructions of the manufacturer. Fluorescence signals were detected using the Affymetrix GeneChip Scanner 3000 (Affymetrix), and average genotyping call rates of 94.4, 91.5 and $97.3 \%$ were obtained for primary tumors, liver metastases and normal peripheral blood DNA samples, respectively.

To identify copy number changes throughout the whole tumor genome, the aroma.affymetrix algorithm was used, following the CRMA v2 method described elsewhere ${ }^{18}$ (R-software package, http:// www.aroma-project.org) and the following sequential steps: (i) calibration for crosstalks between pairs of allele probes; (ii) normalization for probe nucleotide-sequence effects; and (iii) normalization for PCR fragment-length and probe localization effects. Then, data from the 250K StyI and 250K NspI arrays was integrated into a single database, and raw copy number values were calculated as transformed $\log _{2}$ values of the primary tumor/normal peripheral blood, liver metastasis/normal peripheral blood, liver metastases/primary tumor ratios calculated for each individual patient.

To identify DNA regions with similar copy number values, we used Circular Binary Segmentation as implemented in the DNAcopy Bioconductor package ${ }^{19}$ with the default parameters; a $P$-value $\leq 0.01$ for $\geq 5$ markers per DNA segment was used to define points with changes. We used the smoothed value by assigning the median segment value to each probe. For the identification of altered (gained or lost) DNA regions, a threshold was established on the basis of the changes observed in the fluorescence intensity of sequential DNA segments for primary tumor versus peripheral blood, liver metastasis versus peripheral blood, and for liver metastases versus primary tumor samples, for each of the 20 patients studied. $\log _{2}$ ratio values $>0.09$ and $<-0.09$ were used as cut-off thresholds to define the presence of increased and decreased copy number values, respectively. High-level gains (DNA amplification) were defined as regions with a mean $\log _{2}$ copy number ratio $\geq 0.25$. The specific frequencies of both copy number gains and losses per SNP were established and plotted along individual chromosomes for each tumor sample analyzed, for all individual cases studied. On the basis of the empirical frequency distribution of gains and losses among the 20 primary and the 20 metastatic tumor samples, respectively, we took the common altered regions grouping the contiguous SNPs with adjusted $P$-values $<0.01$ (false discovery rate correction, based on the Benjamini and Hochberg procedure). ${ }^{20}$ Minimal common regions were defined as the smallest subset of SNPs in the altered regions with the highest frequency of gains and losses. At least five contiguous SNPs were required to define a region. Genes in these regions were identified using Ensembl release 53 (http://www.ensembl.org). The pattern of copy number changes of the primary tumors analyzed here has been previously reported in detail in a recent study. ${ }^{21}$

\section{Interphase FISH Studies}

To evaluate the reproducibility of the SNP array results and to assess background noise impact of this technique, interphase FISH analyses of the same tumor samples was performed in parallel, using 24 probes directed against an identical number of regions from 20 different human chromosomes, which are frequently altered in sporadic colorectal carcinomas. Overall, our results showed a high degree of correlation between both methods; this also holds true when such analysis was restricted to the most frequently altered regions, as previously described. ${ }^{21}$

\section{Immunohistochemistry}

One block of formalin-fixed paraffin wax-embedded adenocarcinoma tissue was selected in each case. In all cases, this block comprised an area of normal colonic mucosa adjacent to the tumor. Sections $(4 \mu \mathrm{m})$ were affixed to Superfrost-plus slides (CML, Nemours, France) and dried overnight at $37^{\circ} \mathrm{C}$. Paraffin was removed and the tissue rehydrated using xylene and ethanol. Slides were subjected to microwave antigen retrieval in $10 \mathrm{mM}$ citrate buffer (pH 6) at $85^{\circ} \mathrm{C}$ for $35 \mathrm{~min}$ and cooled in phosphatebuffered saline, pH 7.4 (Sigma). Endogenous peroxidase activity was blocked with $2 \%$ hydrogen peroxide in methanol, and slides were washed with phosphate-buffered saline before overnight incubation with the appropriate antibody at a dilution of 
1:100. Commercially available monoclonal antibodies against the nuclear proteins MLH1 (Clone G168-15; BD Biosciences, San Jose, CA, USA), MSH2 (Clone FE11; Biocare Medical, CA, USA) and MSH6 (Clone BC/44; Biocare Medical) were applied, followed by staining with Strept $\mathrm{ABC}$ complex/HRP Duet kit (DAKO, Copenhagen, Denmark) in conjunction with diamino benzedene $180 \mathrm{mg}$ in $300 \mathrm{ml}$ phosphate-buffered saline with $300 \mathrm{ml}$ hydrogen peroxide. Sections were washed under running tap water and then lightly counterstained in Mayer's hematoxylin. Loss of expression was recorded when nuclear staining was absent from all malignant cells, but preserved in normal epithelial and stroma cells. Two observers assessed all cases independently.

\section{Statistical Methods}

For all continuous variables, mean values and their s.d. and range were calculated using the SPSS software package (SPSS 12.0. Chicago, IL USA); for dichotomic variables, frequencies were reported. To evaluate the statistical significance of differences observed between groups, the Mann-Whitney $U$-test and the $\chi^{2}$-test were used for continuous and categorical variables, respectively (SPSS).

\section{Results}

Frequency and Chromosomal Localization of Copy Number Changes in Liver Metastasis from Colorectal Carcinoma

Overall, liver metastases from the 20 colorectal cancer patients analyzed systematically contained those chromosomal abnormalities that were identified in their paired primary colorectal carcinomas; (please note that the later have been previously described in detail for a larger series of patients). ${ }^{21}$ Despite this, some aberrations were either newly acquired or more frequently found in liver metastases than in their paired primary tumors, which could reflect an increased genetic instability of neoplastic cells from metastatic versus primary tumor samples (Figure 1).

In detail, all liver metastases showed copy number changes in at least one chromosomal region. The highest frequency of copy number losses detected corresponded to chromosomes $1 \mathrm{p}(n=16$; $80 \%), 17 \mathrm{p}(n=18 ; 90 \%)$ and $18 \mathrm{q}(n=19 ; 95 \%)$; in turn, copy number gains more frequently involved chromosomes $7 \mathrm{p}(n=18 ; 90 \%), 8 \mathrm{q}(n=15 ; 75 \%)$, $13 \mathrm{q}(n=14 ; 70 \%)$ and $20 \mathrm{q}(n=15 ; 75 \%)$ (see Supplementary Table S1). Interestingly, each of these regions has been previously found to contain
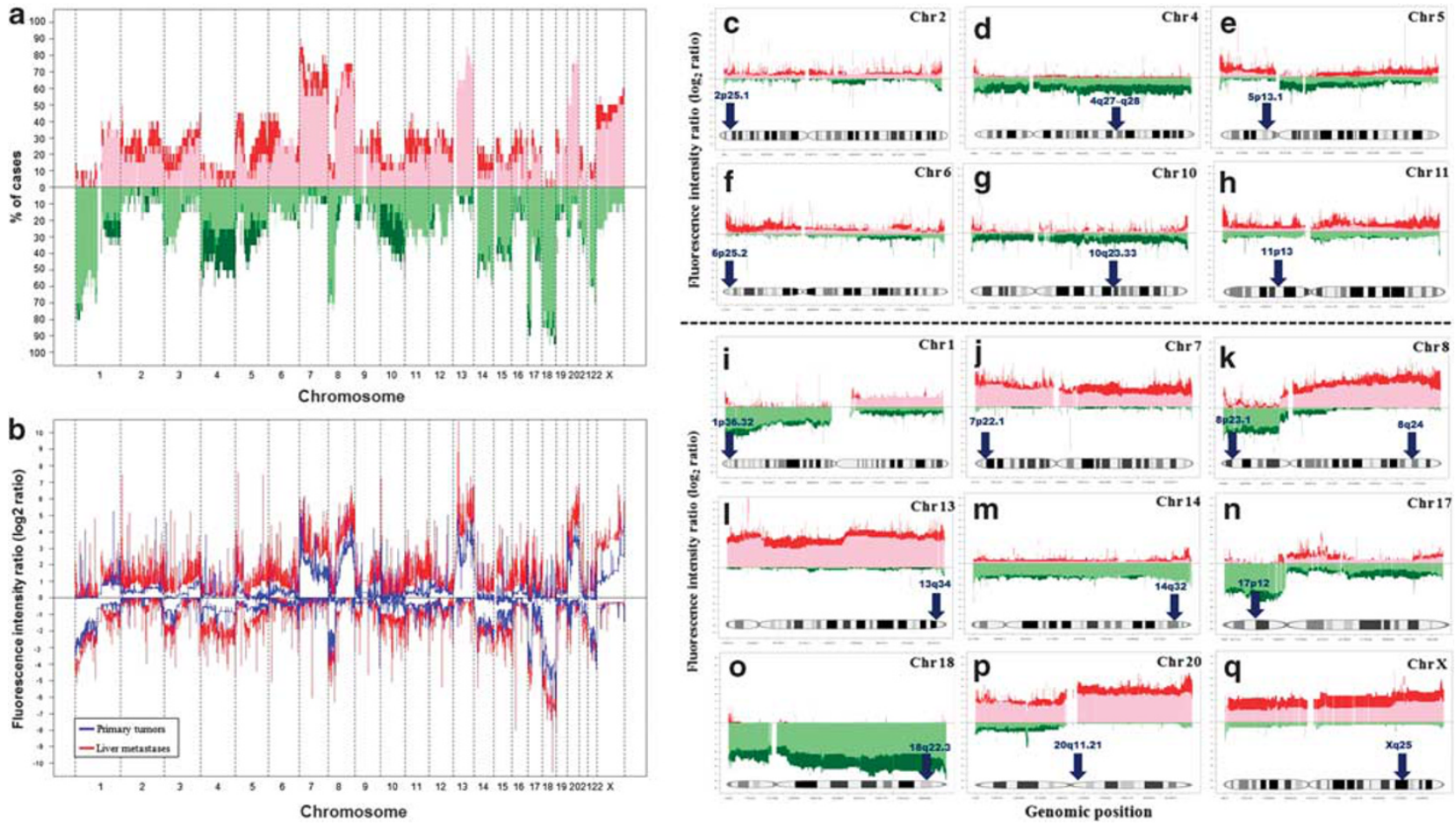

Figure 1 Metastatic colorectal cancer genome for the 20 colorectal carcinoma patients genotyped on the Affymetrix $500 \mathrm{~K}$ SNP array platform. A summary plot showing the frequency (a (in the left)) and fluorescence intensity $\log _{2}$ ratios (b (in the left)) of those copy number gains (plotted in red above zero values in the $x$ axis) and losses (plotted in green below zero values in the $x$ axis) identified in primary sporadic colorectal tumors (light colors), and their paired liver metastases (dark color) are displayed for the whole genome. The panels in the right show abnormalities identified in primary sporadic colorectal tumors (light colors) and their paired liver metastases (dark color) for individual chromosomes, which showed new abnormalities in metastatic versus primary tumor samples (c-h), or displayed an increased frequency of abnormalities in metastatic samples, which were already detected in primary tumors (i-q). Arrows point to regions of interest. 
genes, which are altered/involved in colorectal cancer (eg, ANGPT2, UBR5, KLF10, EIF3H, NOV, DCT, ABCC4, SLC15A1, EFNB2, IRS2, ING1, $M A P 2 K 4$ (mitogen-activated protein kinase kinase4), ID1, BCL2L1, MYLK2, CBFA2T2 and E2F1) and/or genes that are relevant to the metastatic process (eg, ANGPT2, RRM2B, KLF10, RAD21, NOV, POU4F1, SPRY2, DCT, CLDN10, EFNB2, IRS2, COL4A2, ING1, MYH8, MAP2K4, ID1, BCL2L1, TPX2, MYLK2 and $E 2 F 1$ ), in addition to genes associated with other malignancies (ie, TRPS1, BTF3L1, DNAJC3, STK24, TM9SF2, LIG4, ARHGEF7, SCO1, MYOCD, GALR1, $H C K$ and $S M C 1 B$; Table 1). From them, the ANGPT2, $M A P 2 K 4, E 2 F 1$, ID1 and BCL2L1 genes have been reported to be involved in mechanisms that lead to increased cell proliferation and angiogenesis, and they have been found to be altered in both colorectal cancer and the metastatic events.

\section{Frequency and Chromosomal Localization of High- Level Copy Number Gains in Liver Metastases from Colorectal Carcinomas}

Chromosome 7 showed 17 regions, which displayed high level genetic amplification (Table 2) with mean $\log _{2}$ ratio fluorescence intensities of 0.28 (range: 0.25-0.36). These 17 regions were distributed along the whole chromosome 7 at the $7 \mathrm{p} 22,7 \mathrm{p} 21,7 \mathrm{p} 15$, $7 \mathrm{p} 12,7 \mathrm{q} 22$ and $7 \mathrm{q} 36$ chromosome bands, and they were all found to be altered (amplified) in $\geq 14 / 20$ cases studied (70\%; see Supplementary Table S2). These regions contain multiple genes, which have been recurrently associated with the pathogenesis of colorectal cancer and the metastatic process: FSCN1, TWIST1, ITGB8, DFNA5, HOXA7, GRB10, EGFR, AZGP1, MCM7, EPHB4 and MUC3A (Table 2). In turn, for chromosome 8, only two regions of highlevel genetic amplification (mean fluorescence intensities of 0.42 and 0.37 , respectively) were detected; both regions were localized at the 8q24 chromosome band, and they involved the MTSS1 and ASAP1 genes (Table 2). Additionally, chromosomes 13 and 20 also displayed three regions (two in chromosome 13 and one in chromosome 20) with high level genetic amplification (mean fluorescence intensities of 0.45 and 0.43 , respectively), containing genes potentially involved in the pathogenesis of colorectal cancer and the metastatic process, the KLF5 and IRS2 and the MMP9 genes coded in the 13q22.1, 13q34 and 20q13.12 chromosomal regions, respectively (Table 2 ).

\section{Acquired Chromosomal Abnormalities in Liver Metastases}

In individual patients, primary tumors and their paired liver metastases frequently revealed the same chromosomal changes at both sites (Figure 1). However, liver metastases from 8 out of 20 cases showed acquisition of new genetic abnormalities that were not found in their paired primary tumors.

Table 1 Chromosomal regions, which most frequently displayed copy number alterations by SNP arrays, in colorectal liver metastases and that contain genes commonly associated with colorectal cancer and the metastatic process $(n=20)$

\begin{tabular}{|c|c|c|c|c|c|c|}
\hline $\begin{array}{l}\text { Altered chromosomal } \\
\text { regions (bp) }\end{array}$ & $\begin{array}{l}\text { Region length } \\
\quad(\mathrm{bp})\end{array}$ & $\begin{array}{l}\text { Number of } \\
\text { SNPS }\end{array}$ & $\begin{array}{l}\text { Chromosome } \\
\text { band }\end{array}$ & Event & $\begin{array}{c}\text { Altered } \\
\text { cases (\%) }\end{array}$ & Cancer-associated genes \\
\hline Chr8: $6319564-6393980$ & 74416 & 41 & $8 p 23.1$ & Deletion & 70 & $A N G P T 2^{\mathrm{a}}$ \\
\hline Chr8: $102281574-104598943$ & 2317369 & 449 & $8 q 22.3$ & Gain & 75 & RRM2B, UBR $5^{\mathrm{a}}, \mathrm{KLF10}$ \\
\hline Chr8: $116722193-118020419$ & 1298226 & 222 & $8 \mathrm{q} 23.3$ & Gain & 75 & TRPS1, EIF3H $H^{\mathrm{a}}, \boldsymbol{R A D 2 1}$ \\
\hline Chr8: 120491 103-120508049 & 16946 & 8 & $8 q 24.12$ & Gain & 75 & $N O V^{a}$ \\
\hline Chr13: $75649333-83553225$ & 7903892 & 1469 & $13 q 22.3$ & Gain & 70 & BTF3L1, POU4F1, SPRY2 \\
\hline Chr13: $93770996-94062605$ & 291609 & 72 & $13 q 31.3$ & Gain & 70 & $D C T^{\mathrm{a}}$ \\
\hline Chr13: $94410370-94792167$ & 381797 & 118 & $13 q 31.3$ & Gain & 70 & $A B C C 4^{\mathrm{a}}$ \\
\hline Chr13: 94803 129-95 581085 & 777956 & 80 & $13 q 31.3$ & Gain & 70 & CLDN10, DNAJC3 \\
\hline Chr13: $96635106-99063992$ & 2428886 & 530 & $13 q 32.1$ & Gain & 70 & STK24, SLC15A1 ${ }^{\mathrm{a}}, T M 9 S F 2$ \\
\hline Chr13: 105576 623-106 900640 & 1324017 & 327 & $13 \mathrm{q} 33.2$ & Gain & 70 & $E_{F N B 2^{a}}$ \\
\hline Chr13: 107631 285-107 678245 & 46960 & 15 & $13 q 33.3$ & Gain & 70 & LIG4 \\
\hline Chr13: 109092 251-110 808910 & 1716659 & 406 & $13 \mathrm{q} 34$ & Gain & 70 & IRS2, COL4A2, ING1 ${ }^{\mathrm{a}}, A R H G E F 7$ \\
\hline Chr17: $10134845-11066755$ & 931910 & 178 & $17 \mathrm{p} 13.1$ & Deletion & 90 & МYH8, SCO1 \\
\hline Chr17: $11124244-12787020$ & 1662776 & 312 & $17 \mathrm{p} 12$ & Deletion & 90 & MAP2K4 ${ }^{\mathrm{a}}, M Y O C D$ \\
\hline Chr18: $71151155-73487286$ & 2336131 & 645 & $18 \mathrm{q} 22.3$ & Deletion & 95 & GALR1 \\
\hline Chr20: 29314 247-30 386296 & 1072049 & 103 & $20 q 11.21$ & Gain & 75 & ID1, BCL2L1 ${ }^{\mathrm{a}}, \boldsymbol{T P X 2}, H C K, M Y L K 2^{\mathrm{a}}$ \\
\hline Chr20: $31377143-32096987$ & 719844 & 81 & $20 \mathrm{q} 11.21$ & Gain & 75 & $C B F A 2 T 2^{\mathrm{a}}, \boldsymbol{E 2} \mathbf{F 1}^{\mathrm{a}}$ \\
\hline Chr22: $44114817-44172947$ & 58130 & 16 & $22 q 13.2$ & Deletion & 70 & $S M C 1 B$ \\
\hline
\end{tabular}

${ }^{\mathrm{a}}$ Genes that have been described to be involved/altered in colorectal cancer, and genes that have been commonly associated with the metastatic process are shown in bold italics. 
Table 2 Chromosomal regions, which most frequently displayed high-level genetic amplification by SNP arrays, and which contained genes commonly involved/altered in colorectal cancer and/or associated with the metastatic process $(n=20)$

\begin{tabular}{|c|c|c|c|c|c|}
\hline $\begin{array}{l}\text { Amplified chromosomal } \\
\text { regions (bp })^{\mathrm{a}}\end{array}$ & $\begin{array}{l}\text { Chromosomal } \\
\text { band }\end{array}$ & $\begin{array}{l}\text { Mean } \log _{2} \\
\text { ratio }\end{array}$ & $\begin{array}{l}\text { Maximum } \\
\log _{2} \text { ratio }\end{array}$ & $\begin{array}{l}\text { Altered } \\
\text { cases }(\%)\end{array}$ & Cancer-associated genes \\
\hline Chr7: 2888 108-2 965622 & $7 \mathrm{p} 22.2$ & 0.26 & 1.40 & 80 & CARD11 \\
\hline Chr7: 4624 574-5 634592 & $7 \mathrm{p} 22.1$ & 0.26 & 1.13 & 85 & $F_{S C N 1}{ }^{\text {b }}$ \\
\hline Chr7: 19099 597-19164 657 & $7 \mathrm{p} 21.1$ & 0.29 & 1.33 & 80 & TWIST1 $^{\mathrm{b}}$ \\
\hline Chr7: 20315 252-20 348199 & 7p15.3 & 0.26 & 0.93 & 80 & $I T G B 8^{b}$ \\
\hline Chr7: 24288 850-24 294445 & $7 \mathrm{p} 15.3$ & 0.28 & 1.68 & 80 & $N P Y^{\mathrm{b}}$ \\
\hline Chr7: $24761544-24764289$ & 7p15.3 & 0.27 & 1.45 & 80 & $D F N A 5^{\mathrm{b}}$ \\
\hline Chr7: $27110282-27278326$ & $7 \mathrm{p} 15.2$ & 0.36 & 1.67 & 70 & $\begin{array}{c}\text { HOXA5, HOXA7 }, \text { HOXA9, } \\
\text { HOXA11, HOXA13 }\end{array}$ \\
\hline Chr7: 28169 667-28 211202 & $7 \mathrm{p} 15.2$ & 0.28 & 1.19 & 70 & $J A Z F 1$ \\
\hline Chr7: $50163751-50752627$ & $7 \mathrm{p} 12.2$ & 0.27 & 1.93 & 75 & $I K Z F 1, D D C$ \\
\hline Chr7: $50797965-50839403$ & $7 \mathrm{p} 12.2$ & 0.32 & 1.41 & 75 & SLC4A2, FASTK \\
\hline Chr7: $50797965-50839403$ & $7 \mathrm{p} 12.2$ & 0.33 & 1.42 & 75 & $G_{R B 10}$ \\
\hline Chr7: 54954 150-56 213585 & $7 \mathrm{p} 11.2$ & 0.27 & 1.10 & 75 & $\boldsymbol{E G F R}^{\mathrm{b}}, P S P H$ \\
\hline Chr7: 99301 754-101811250 & $7 \mathrm{q} 22.1$ & 0.25 & 0.70 & 70 & $\begin{array}{c}A Z G P 1^{\mathrm{b}}, M C M 7^{\mathrm{b}}, C U X 1, E P H B 4^{\mathrm{b}} \\
M_{M U C 3 A^{\mathrm{b}}, M U 12^{\mathrm{b}}}\end{array}$ \\
\hline Chr7: $105711183-105715751$ & $7 \mathrm{q} 22.2$ & 0.25 & 0.88 & 70 & $P B E F 1$ \\
\hline Chr7: $154677722-155005086$ & $7 \mathrm{q} 36.3$ & 0.27 & 0.91 & 70 & EN2 \\
\hline Chr7: $156357544-156630253$ & $7 \mathrm{q} 36.3$ & 0.28 & 0.63 & 70 & MNX1, UBE3C \\
\hline Chr7: $156893472-158147850$ & $7 \mathrm{q} 36.3$ & 0.29 & 1.34 & 70 & PTPRN2 \\
\hline Chr8: $125800442-125834484$ & $8 q 24.13$ & 0.42 & 1.19 & 85 & MTSS1 \\
\hline Chr8: $131064043-131191826$ & $8 \mathrm{q} 24.21$ & 0.37 & 0.98 & 70 & $A S A P 1^{\mathrm{b}}$ \\
\hline Chr13: $72497695-72659497$ & $13 q 22.1$ & 0.41 & 0.73 & 70 & $K L F 5^{\mathrm{b}}$ \\
\hline Chr13: $79810102-79825947$ & $13 q 31.1$ & 0.46 & 1.39 & 70 & SPRY2 \\
\hline Chr13: 90792 026-90 811945 & $13 q 31.3$ & 0.47 & 1.50 & 70 & MIRHG1 \\
\hline Chr13: 98007 816-98 035844 & $13 q 32.2$ & 0.43 & 1.49 & 70 & STK24 \\
\hline Chr13: 109205 907-109255030 & $13 q 34$ & 0.44 & 1.20 & 70 & $I R S 2^{\mathrm{b}}$ \\
\hline Chr13: 109743 976-109764 350 & $13 q 34$ & 0.47 & 1.47 & 70 & COL4A1, COL4A2 \\
\hline Chr13: $110549062-110578598$ & $13 q 34$ & 0.45 & 1.79 & 70 & ARHGEF7 \\
\hline Chr20: $41247578-41278159$ & $20 q 12$ & 0.41 & 1.10 & 70 & PTPRT \\
\hline Chr20: $44007866-44178129$ & $20 q 13.12$ & 0.41 & 0.88 & 70 & $M M P 9^{b}$ \\
\hline Chr20: $59241454-59268793$ & $20 q 13.33$ & 0.47 & 1.8 & 70 & $C D H 4^{\mathrm{b}}$ \\
\hline
\end{tabular}

${ }^{\mathrm{a}}$ Only those regions, which were recurrently amplified in at least 14 out of 20 cases analyzed ( $>70 \%$ ) are listed.

${ }^{\mathrm{b}}$ Genes that have been described to be involved/altered colorectal cancer, and genes that have been commonly associated with metastatic processes are shown in bold italics.

High-level genetic amplification was defined versus those with an average $\log _{2}$ copy number ratio $\geq 0.25$.

These new metastatic aberrations included copy number gains at chromosomes $2 p, 5 p, 6 p, 7 q$ and $11 \mathrm{p}$, together with copy number losses of chromosomes $4,5 q$ and $10 q$ (Table 3 ). The specific abnormalities, which were recurrently detected in 8 out of 20 colorectal carcinomas metastasis for those chromosomal regions that showed a normal diploid profile in their corresponding (paired) primary tumors, are shown in Figure 2. As illustrated, these metastatic abnormalities involved chromosomal regions which harbor i) tumor suppressor genes that have a key role in the metastatic process (eg, the ANXA5, CCNA2, IL2 and IL21 genes at chromosome 4q27; the PLK4, IL15, GAB1, HHIP and SMAD1 genes coded at the 4q28.1 chromosome regions and the PTEN gene coded at the 10q23.33 chromosomal region) and; (ii) oncogenes (eg, the PTGER4 and PRKAA1 genes coded at chromosome 5p13.1, and both the RIPK1 and NQO2 genes coded at chromosome 6p25.2); copy number gains of the former two oncogenes have been associated with advanced colorectal carcinoma. Many other genetic aberrations were present in liver metastases from colorectal carcinoma analyzed, but at lower frequencies (Figure 1).

\section{Correlation Between the Chromosomal Changes Detected by Interphase FISH and SNP Array Studies}

Overall, the chromosomal abnormalities identified by interphase FISH in liver metastases showed profiles similar to those found by SNP array studies, also when such analysis was restricted to the most frequently altered regions. Thus, gains/amplification at $7 \mathrm{q}$ were detected in $60 \%$ of the cases by interphase FISH versus $70 \%$ by SNP array studies $\left(r^{2}=0.67 ; P<0.001\right)$; similarly, gains/amplification of chromosomes 8q (found in $70 \%$ of cases by interphase FISH vs $75 \%$ by SNP array studies; 
Table 3 Metastatic colorectal cancer genome for the 20 colorectal cancer patients genotyped on the Affymetrix $500 \mathrm{~K}$ SNP array platform: chromosomal abnormalities identified exclusively in liver metastases (and not in their paired primary tumors), which involved chromosomal regions that contain genes commonly associated with cancer and/or the metastatic process

\begin{tabular}{|c|c|c|c|c|c|}
\hline $\begin{array}{l}\text { Altered chromosomal } \\
\text { regions (bp) }\end{array}$ & $\begin{array}{l}\text { Chromosome } \\
\text { band }\end{array}$ & Event & $\begin{array}{l}\text { Number of } \\
{\text { altered } \text { cases }^{\mathrm{a}}}\end{array}$ & $\begin{array}{l}\text { Mean } \log _{2} \text { ratio in } \\
\text { liver metastases }\end{array}$ & Cancer-associated genes \\
\hline Chr2: $11301969-11420624$ & $2 \mathrm{p} 25.1$ & Gain & 7 & 1.13 & - \\
\hline Chr4: 11217 752-12 280681 & $4 \mathrm{p} 15.33$ & Deletion & 7 & -23.76 & - \\
\hline Chr4: $12402361-14483843$ & 4p15.33 & Deletion & 7 & -53.43 & - \\
\hline Chr4: 14537 247-16 743438 & 4p15.33 & Deletion & 7 & -48.17 & 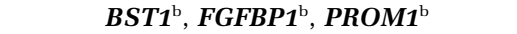 \\
\hline Chr4: 95174 065-97996020 & $4 q 22.3$ & Deletion & 7 & -58.56 & BMPR1B $^{\mathrm{b}}$ \\
\hline Chr4: $98021823-101566164$ & $4 \mathrm{q} 22.3$ & Deletion & 7 & -55.19 & $\boldsymbol{E I F 4 E}^{\mathrm{b}}, A D H 5, \boldsymbol{M T T P}^{\mathrm{b}}$ \\
\hline Chr4: $122461059-126659227$ & $4 q 27$ & Deletion & 8 & -61.43 & 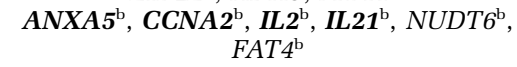 \\
\hline Chr4: $126668154-147205681$ & $4 q 28.1$ & Deletion & 8 & -324.84 & 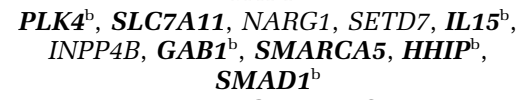 \\
\hline Chr4: $147218521-148654896$ & $4 \mathrm{q} 31.22$ & Deletion & 7 & -26.13 & EDNRA, POU4F2, LSM6 \\
\hline Chr4: $148658165-150007154$ & $4 \mathrm{q} 31.23$ & Deletion & 7 & -24.35 & EDNRA, ARHGAP10, NR3C2 ${ }^{\mathrm{b}}$ \\
\hline Chr4: $151081476-169411644$ & $4 q 31.3$ & Deletion & 7 & -317.79 & 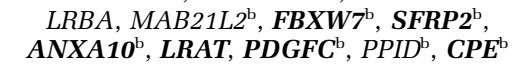 \\
\hline Chr4: $171433995-173576567$ & $4 q 33$ & Deletion & 7 & -37.39 & (2) \\
\hline Chr4: 175432 179-176 373292 & $4 \mathrm{q} 34.1$ & Deletion & 8 & -17.93 & $H P G D^{\mathrm{b}}$ \\
\hline Chr4: 176393 349-181031 240 & $4 \mathrm{q} 34.2$ & Deletion & 7 & -93.92 & $V E \boldsymbol{E F} \boldsymbol{C}^{\mathrm{b}}$ \\
\hline Chr4: $181036139-183912221$ & $4 \mathrm{q} 34.3$ & Deletion & 8 & -81.56 & - \\
\hline Chr4: $183917599-185620740$ & $4 \mathrm{q} 35.1$ & Deletion & 7 & -28.21 & $I R F 2^{\mathrm{b}}, D C T D^{\mathrm{b}}, I N G 2^{\mathrm{b}}$ \\
\hline Chr4: 188066 517-189969188 & $4 \mathrm{q} 35.2$ & Deletion & 8 & -31.94 & $Z F P 42$ \\
\hline Chr5: $31602359-32770165$ & $5 p 13.1$ & Gain & 7 & 17.03 & NPR3, PDZD2 \\
\hline Chr5: $40710736-40901620$ & $5 \mathrm{p} 13.1$ & Gain & 8 & 1.55 & PTGER4 ${ }^{\mathrm{b}}$, PRKAA1 ${ }^{\mathrm{b}}$ \\
\hline Chr5: $42953413-43243995$ & $5 p 12$ & Gain & 7 & 3.87 & - \\
\hline Chr5: $43501986-43901209$ & 5p12 & Gain & 7 & 2.68 & - \\
\hline Chr5: $58935951-59201448$ & $5 q 12.1$ & Deletion & 6 & -6.29 & - \\
\hline Chr5: $141299822-141552149$ & $5 q 31.3$ & Gain & 7 & 2.14 & $R N F 14^{\mathrm{b}}$ \\
\hline Chr6: $1310265-1608630$ & $6 \mathrm{p} 25.3$ & Gain & 7 & 7.89 & - \\
\hline Chr6: $2713210-3252280$ & $6 \mathrm{p} 25.2$ & Gain & 8 & 9.74 & $\begin{array}{c}\boldsymbol{R I P K 1}^{\mathrm{b}}, \boldsymbol{N Q O 2}^{\mathrm{b}}, \text { SERPINB1, SERPINB6 } \\
\text { SERPINB9 }\end{array}$ \\
\hline Chr6: $3391923-3411021$ & $6 \mathrm{p} 25.2$ & Gain & 8 & 0.98 & - \\
\hline Chr6: $3663243-3673023$ & $6 \mathrm{p} 25.2$ & Gain & 8 & 0.90 & - \\
\hline Chr6: 4026 261-4 342058 & $6 \mathrm{p} 25.2$ & Gain & 7 & 5.45 & - \\
\hline Chr6: $4840846-5220281$ & $6 \mathrm{p} 25.1$ & Gain & 7 & 7.36 & - \\
\hline Chr6: 5493 557-5 966877 & $6 \mathrm{p} 25.1$ & Gain & 7 & 7.00 & - \\
\hline Chr6: 6476 360-6 654484 & $6 \mathrm{p} 25.1$ & Gain & 7 & 4.22 & - \\
\hline Chr6: $7647658-7683958$ & $6 \mathrm{p} 24.3$ & Gain & 8 & 1.18 & $B M P 6^{b}$ \\
\hline Chr6: $10495977-10532295$ & $6 \mathrm{p} 24.3$ & Gain & 7 & 0.96 & $T F A P 2 A^{\mathrm{b}}$ \\
\hline Chr6: $13593062-13758950$ & $6 \mathrm{p} 23$ & Gain & 7 & 2.08 & - \\
\hline Chr6: 13857 081-14 361384 & $6 \mathrm{p} 23$ & Gain & 7 & 6.40 & - \\
\hline Chr6: $15143396-15884421$ & $6 \mathrm{p} 23$ & Gain & 7 & 8.47 & $\mathrm{CD83}^{\mathrm{b}}$ \\
\hline Chr6: $16085720-16448755$ & $6 \mathrm{p} 22.3$ & Gain & 7 & 4.71 & - \\
\hline Chr6: $17210737-18442309$ & $6 \mathrm{p} 22.3$ & Gain & 7 & 12.44 & NRN1, DEK, BPHL, RIPK1 ${ }^{\mathrm{b}}$ \\
\hline Chr7: $158430322-158640662$ & $7 q 36.3$ & Gain & 7 & 3.79 & - \\
\hline Chr10: 71077 186-71 425507 & $10 \mathrm{q} 13.2$ & Deletion & 6 & -10.26 & - \\
\hline Chr10: $83990316-84564355$ & 10q23.1 & Deletion & 6 & -9.53 & - \\
\hline Chr10: $89574656-89676489$ & $10 \mathrm{q} 23.2$ & Deletion & 7 & -1.89 & $P T E N^{\mathrm{b}}$ \\
\hline Chr10: 97903 413-100 323090 & $10 \mathrm{q} 23.33$ & Deletion & 6 & -21.38 & 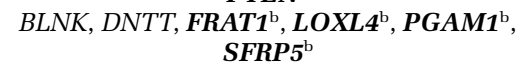 \\
\hline Chr11: 32104 370-34 401072 & $11 \mathrm{p} 13$ & Gain & 6 & 17.60 & LMO2, НIPКЗ, WT $\mathbf{1}^{\mathrm{b}}$ \\
\hline Chr11: $43653493-45414563$ & $11 \mathrm{p} 11.2$ & Gain & 6 & 19.81 & $\boldsymbol{C D 8 2}^{\mathrm{b}}, \boldsymbol{E X T 2}^{\mathrm{b}}, A L K B H 3$ \\
\hline
\end{tabular}

${ }^{\mathrm{a}}$ Number of cases with chromosomal abnormalities identified exclusively in liver metastases and not in their paired primary tumors.

${ }^{\mathrm{b}}$ Genes that have been described to be altered/involved in colorectal cancer, and genes that have been commonly associated with the metastatic process are shown in bold italics.

$\left.r^{2}=0.79 ; \quad P<0.001\right), \quad 13 q \quad\left(80 \quad\right.$ vs $\quad 70 \% ; \quad r^{2}=0.78$ $P<0.001)$ and $20 \mathrm{q}\left(80 \mathrm{vs} 75 \% ; r^{2}=0.80 ; P<0.001\right)$, as well as deletions of chromosomes $8 \mathrm{p}$ (65 vs $70 \%$; $\left.r^{2}=0.81 ; \quad P<0.001\right), \quad 17 \mathrm{p} \quad\left(75\right.$ vs $90 \% ; \quad r^{2}=0.64$; $\mathrm{p}=0.02)$ and $18 \mathrm{q}\left(75\right.$ vs $\left.95 \% ; r^{2}=0.63 ; \mathrm{p}=0.03\right)$ were detected at similar frequencies with both methods.

\section{Microsatellite Status}

All primary tumors examined $(n=20)$ showed a normal expression of the MLH1, MSH2 and MSH6 mismatch repair proteins in the nucleus and adjacent non-neoplastic tissue elements. 

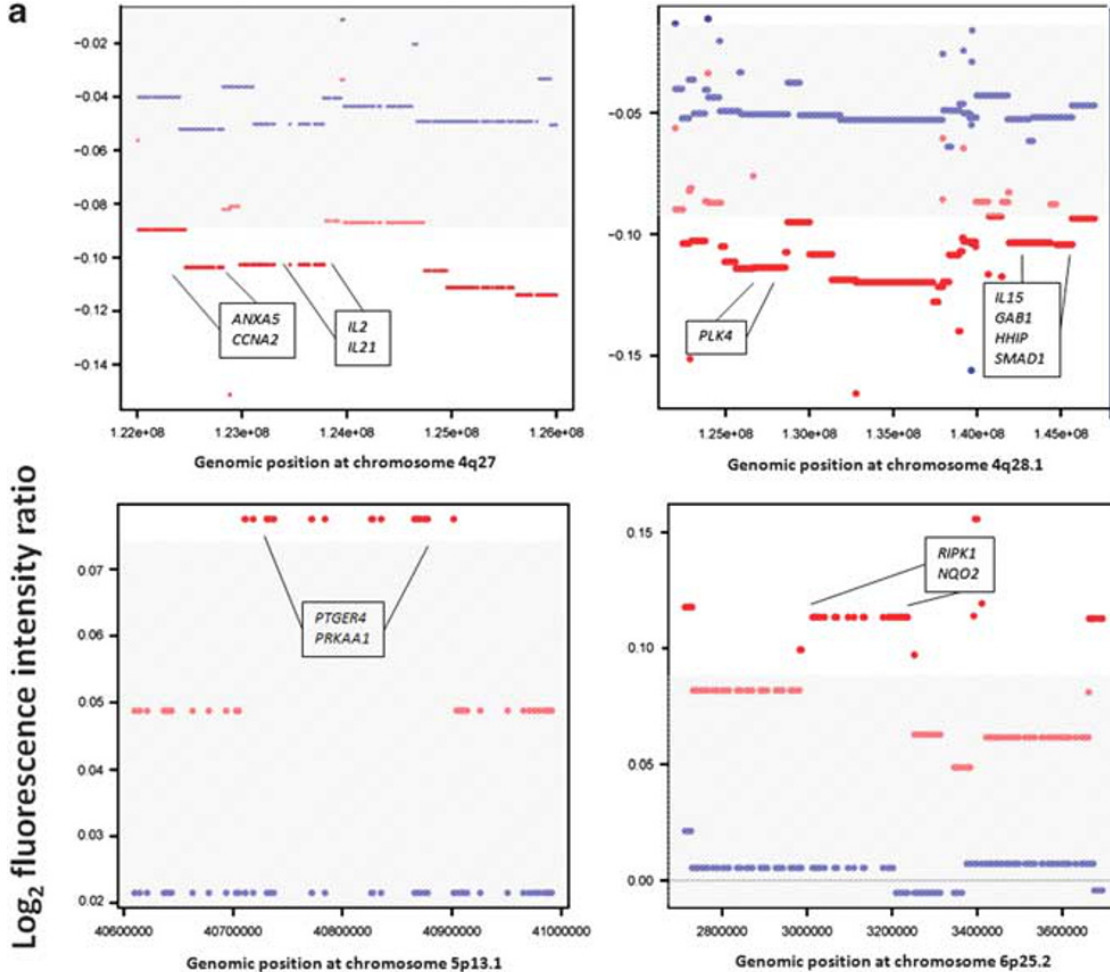

Genomic position at chromosome $4 \mathrm{q} 28.1$
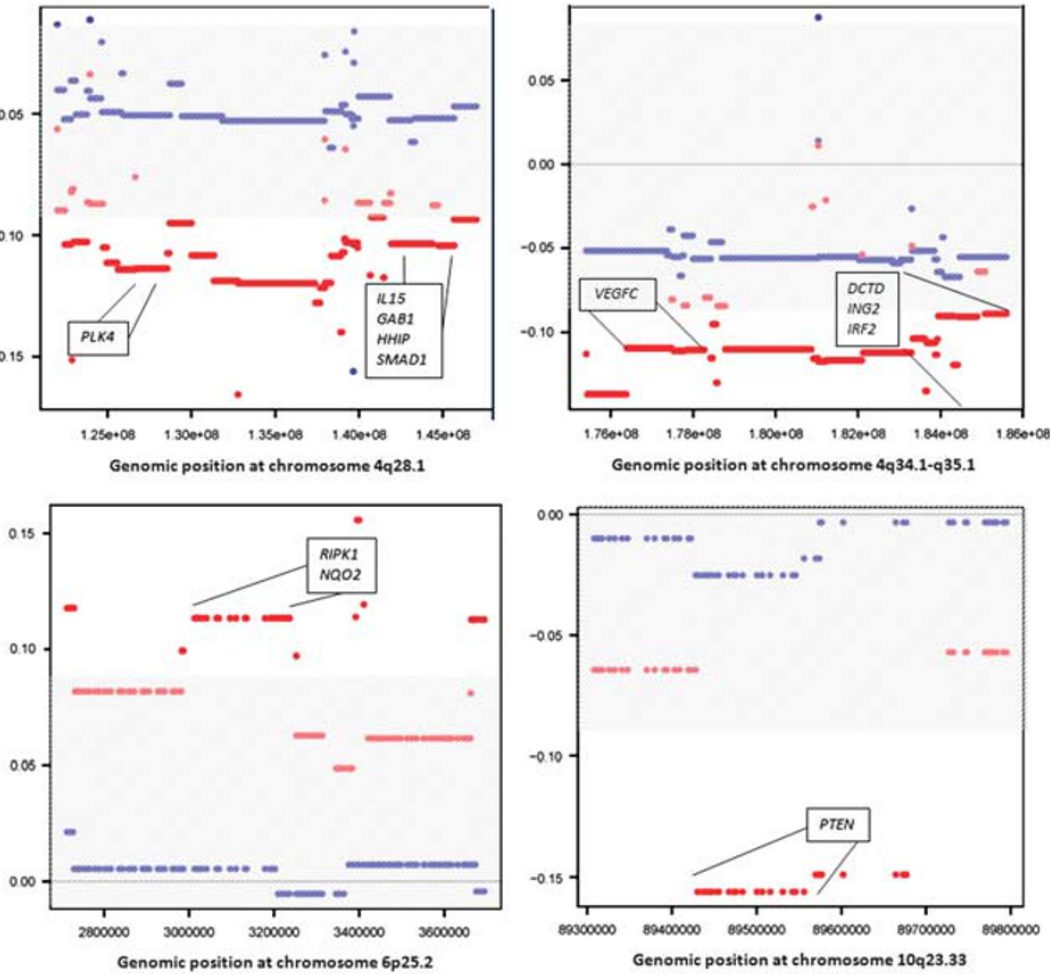

Genomic position at chromosome 4q34.1-q35.1
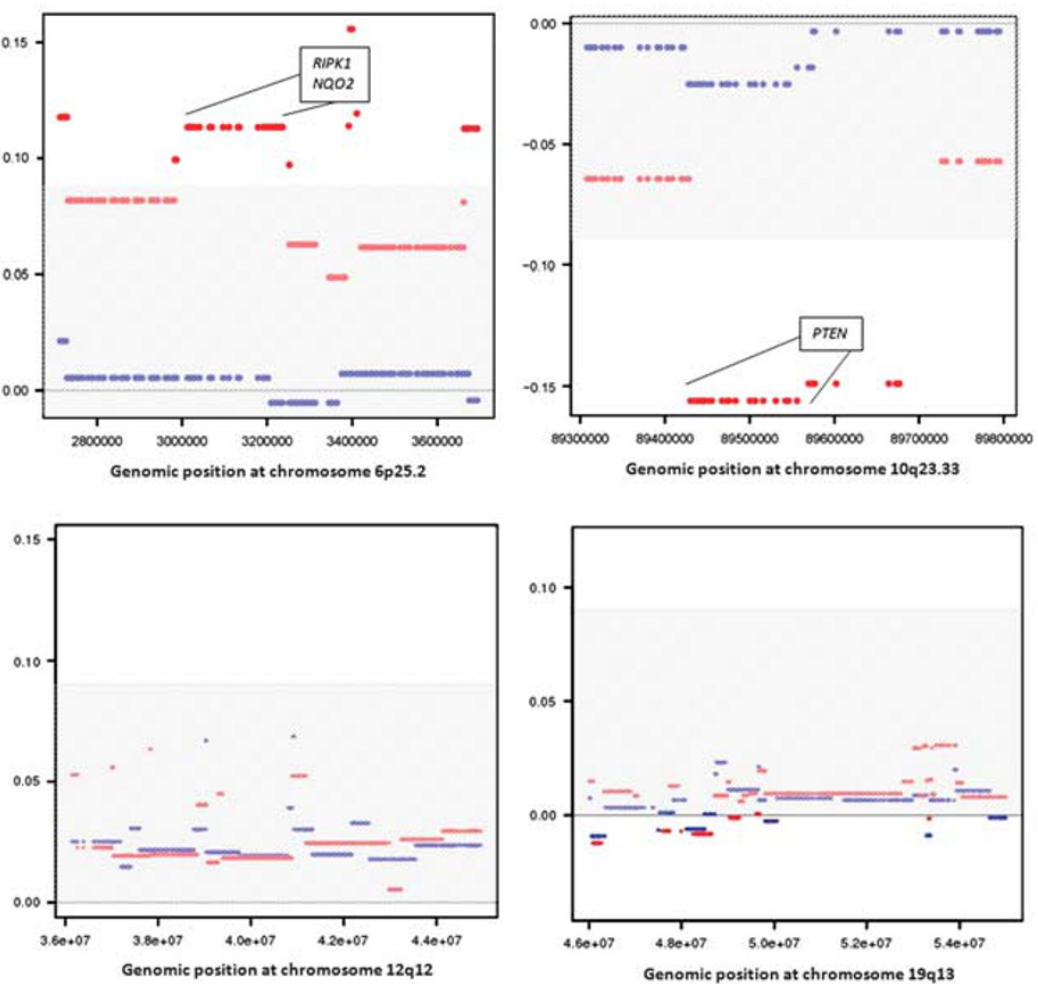

Figure 2 Metastatic colorectal cancer genome for the 20 colorectal carcinoma patients genotyped on the Affymetrix $500 \mathrm{~K}$ SNP array platform; copy number changes detected in liver metastases $(n=8 / 20$ cases; red color) versus their paired primary tumors (blue color) for the 4q27, 4q28.1, 4q34.1, 5p13.1, 6p25.2 and 10q23.33 chromosomal regions (a). Genes contained in the newly altered chromosomal regions are listed in italics capital letters. $\log _{2}$ ratios $>0.09$ and $<-0.09$ (shown as colored background) were used as cut-off thresholds to define the presence of increased and decreased copy number values, respectively. All copy number changes detected between liver metastases versus their paired primary tumors showed statistically significant differences $(P<0.001)$. As an example, the 3p14, 12q12 and 19q13 chromosomal regions, which did not show any differences between paired primary and metastatic lesions, are also shown (b).

\section{Discussion}

This study focused on the genetic characterization of liver metastases that occur in the context of primary colorectal carcinoma. To the best of our knowledge, this is the first study that compares the genetic abnormalities found in liver metastases versus paired primary colorectal tumors, in which high-resolution $500 \mathrm{~K}$ SNP arrays have been systematically used. Overall, primary tumors and their paired metastases from individual patients frequently revealed many common chromosomal changes at both sites; these findings support the existence of a close genetic relationship between primary colorectal tumors and their paired liver metastases, as previously suggested. ${ }^{17}$ Genetic changes observed in common in both groups of samples included gains of chromosomes $7,8 q, 13 q$ and 20 and losses of the $1 p, 4,8 p, 17 p, 18$ and $22 q$ chromosomes with normal expression of the MLH1, MSH2 and MSH6 mismatch repair proteins. In line with other studies, all our metastatic tumors showed a higher frequency of these chromosomal abnormalities than primary colorectal tumors, ${ }^{7,22}$ and some of these abnormalities, together with deletions on chromosome 15q, have been associated with disease progression..$^{23}$ Previous studies in which the genetic abnormalities of colorectal carcinoma have been 
investigated by conventional cytogenetics, ${ }^{24} \mathrm{FISH},{ }^{17}$ $\mathrm{CGH},{ }^{25}$ array $\mathrm{CGH}^{26}$ and low-resolution $50 \mathrm{~K}$ SNP arrays $^{23}$ have also found that most of these genetic abnormalities are recurrently identified in primary tumors from metastatic colorectal carcinoma. On the basis of the high frequency of these chromosomal abnormalities in both primary and metastatic samples, it could be hypothesized that they reflect a metastatic genetic profile of colorectal carcinoma that could be of great clinical utility for the identification of colorectal carcinoma patients at higher risk of developing liver metastases, already at diagnosis.

Interestingly, high-level genetic amplification was found at specific regions of chromosomes 7, 8, 13 and 20; overall, 43 genes commonly involved/ altered in colorectal cancer and/or associated with the metastatic process are coded in these regions. Of note, 17 of these 43 genes have been associated with progression of hepatocellular carcinomas. ${ }^{27-29}$ Altogether, these findings could suggest that these genetic abnormalities that are acquired by metastatic colorectal carcinoma cells in the liver could be associated with homing and/or adaptation to the liver microenvironment. Among these genes, overexpression of TWIST1 has been demonstrated to induce angiogenesis; at the same time, it has been associated with both the development of metastasis in hepatocellular carcinomas ${ }^{30}$ and an unfavorable outcome in colorectal carcinoma patients; ${ }^{31}$ in turn, increased expression of IRS2-commonly found in human hepatocellular carcinoma specimens and hepatoma cell lines- ${ }^{32}$ has been associated with colon tumorigenesis, in which it contributes to tumor progression and an aggressive clinical behavior. $^{33}$ In line with this hypothesis, preliminary studies on genomic differences detected in primary colorectal carcinomas versus paired brain metastases have described a genetic profile consisting of gains of $8 q, 12 p, 12 q, 20 p$, and loss of $5 q$ in brain metastasis, ${ }^{34}$ which is clearly different from that observed in our liver metastases. The different genetic signature associated with liver versus brain metastases could mirror the unique adaptation process of metastatic tumor cells to each specific microenvironment. Despite these findings, those three chromosomal regions, which showed the highest levels of amplification, were 13q31.3, $13 q 34$ and 20q13.33, where four known cancer genes (MIRHG1,COL4A1, COL4A2 and CDH4) are coded. To the best of our knowledge, no specific association between amplification of these genes and colorectal carcinoma has been reported so far; conversely, deregulation of these genes has been associated with neuroblastoma, ${ }^{35}$ esophageal squamous cell carcinoma ${ }^{36}$ and glioblastoma multiforme. ${ }^{37}$

In the present study, we also show the existence of recurrent genetic changes between paired primary and metastatic colorectal tumor cells. Such changes mainly consist of (1) an increased frequency of genetic lesions of chromosomes that have been associated with metastatic colorectal carcinoma (1p, 7p, 8q, 13q, 17p, 18q, 20q) and, more interestingly, (2) acquisition of new chromosomal abnormalities (eg, losses of chromosomes 4 and $10 \mathrm{q}$ and gains of chromosomes $5 \mathrm{p}$ and $6 \mathrm{p}$ ). Interestingly, the former abnormalities involved chromosomal regions that encode for up to 11 genes, which have been previously found to be involved in the metastatic process of colorectal carcinoma. As an example, the ANGPT2 gene (localized in chromosome 8 at 8p23.1) is known to be involved in angiogenic processes and has been previously associated with an invasive/malignant potential; ${ }^{38}$ in turn, the E2F1 gene (20q11.21) has been shown to have a crucial role in the control of cell cycle through downregulation of tumor suppressor proteins. ${ }^{39}$ Similarly, the ID1 and BCL2L1 genes (both coded in the same chromosomal region at $20 q 11.21$ ) are also known to have a role in cell growth, senescence and differentiation, and the carcinogenesis of human colorectal carcinoma, ${ }^{40}$ whereas overexpression of the Id1 protein has been associated with tumor progression in colorectal carcinoma. ${ }^{41}$ In turn, Paredes et $a 1^{11}$ have recently described that losses of chromosome $17 \mathrm{p}$ in metastatic colorectal cancer samples cover larger regions than in primary tumors, suggesting that additional unknown suppressor genes could be present at 17p, in the newly deleted sequences. In line with these findings, we have recurrently identified loss of the $M A P 2 K 4$ gene at 17 p12 in the great majority of the metastatic samples analyzed. The $M A P 2 K 4$ gene is a member of the stress-activated protein kinase signaling cascade involved in the regulation of multiple cellular processes, which among other associations, has been recently suggested to have a functional role as a metastasis-suppressor gene in several malignant tumors, for example, human prostatic cancer, ${ }^{42}$ ovarian cancer, ${ }^{43}$ as well as breast and pancreatic tumors. ${ }^{44}$ Similarly, a potential role for $18 \mathrm{q} \mathrm{LOH}$ in the development of colorectal cancer with associated liver metastases has been suggested, ${ }^{10}$ as well as its potential independent prognostic value, ${ }^{45}$ which may depend on the microsatellite instability status. ${ }^{46}$ In this regard, chromosomal instability has been associated in colorectal cancer with a worse prognosis, and different groups of tumors have been defined on the basis of the chromosomal instability status. ${ }^{47}$ Herein, we identified loss of the $18 q 22-q 23$ chromosomal region in the great majority (95\%) of the metastatic samples analyzed; interestingly, no clear association could be found between $18 \mathrm{q} \mathrm{LOH}$ and the microsatellite instability status, because of normal expression of the MLH1, MSH2 and MSH6 mismatch repair genes, and potentially, also the relatively limited number of cases studied. Similarly, the sample size and the presence of multiple structural and/or numerical chromosome changes in all liver metastases analyzed precludes the study of chromosomal instability subtypes. 
Many patients also showed acquisition of new genetic aberrations, which were not detected in their paired primary tumors. These included gains of chromosomes 2, 5p, 6p, $7 \mathrm{q}$ and $11 \mathrm{p}$, and losses of chromosomes 4 and 10q. These results suggest that these chromosomal regions may also have a relevant role in the metastatic process as supported by the fact that some of them-for example, $\operatorname{del}(4 \mathrm{p} 15.33)$, $\operatorname{del}(4 q 22.3), \quad \operatorname{del}(4 q 27), \quad \operatorname{del}(4 q 28.1), \quad \operatorname{del}(4 q 31)$, $\operatorname{del}(4 q 35.1)$ and del(10q23)—are known to contain multiple tumor suppressor genes (eg, PLK4 at 4q28.1, SFRP2 at 4q31.3, IRF2 at 4q35.1 and PTEN at $10 \mathrm{q} 23.2)^{48-51}$ and genes that are involved in the metastatic process. ${ }^{52-54}$ In line with these findings, previous studies in which primary colorectal carcinomas were compared with liver metastases also reported a greater frequency of chromosome 4 losses in late versus early stages of the disease. ${ }^{9,55}$ However, due to the limited sensitivity of the SNP array technique for the detection of small clones that could already be present in primary tumors, further studies in which such abnormalities are investigated at the single-cell level are required to confirm our findings.

In summary, here we show the existence of relevant genetic differences between paired primary and metastatic colorectal tumors, which mainly consist of (1) an increased frequency of genetic lesions of chromosomes that have been associated with metastatic colorectal cancer (1p, 7p, 8q, 13q, $17 p, 18 q, 20 q)$ and, more interestingly, (2) acquisition of new chromosomal abnormalities (eg, losses of chromosomes 4 and $10 \mathrm{q}$ and gains of chromosomes $5 p$ and $6 p$ ). These genetic changes acquired by metastatic tumors may be associated with either the metastatic process and/or adaption of metastatic cells to the liver microenvironment. Further studies in larger series of patients, in which cases with nonresecable liver metastasis are also analyzed, are necessary to dissect the specific role of each of the altered genes and chromosomal regions in the metastatic spread of colorectal tumors. Additional gene expression profile studies are required to validate the proteins associated with copy number alterations in the metastasis versus the primary tumor.

\section{Acknowledgements}

This work has been partially supported by grants from the Consejería de Sanidad, Junta de Castilla y León, Valladolid, Spain (SAN191/SA09/06, SAN673/SA39/08 and SAN/103/2011), Fundación Memoria de Don Samuel Solórzano Barruso, Salamanca, Spain, Caja de Burgos (Obra Social), Burgos, Spain, Grupo Excelencia de Castilla y León (GR37) and the RTICC from the Instituto de Salud Carlos III (ISCIII), Ministerio de Sanidad y Consumo, Madrid, Spain (RD06/0020/0035-FEDER). JM Sayagués and M González are supported by grants (CP05/00321 and FI08/00721, respectively) from the ISCIII, Ministerio de Ciencia e Innovación, Madrid, Spain.

\section{Disclosure/conflict of interest}

The authors declare no conflict of interest.

\section{References}

1 Tsai HL, Lu CY, Hsieh JS, et al. The prognostic significance of total lymph node harvest in patients with T2-4N0M0 colorectal cancer. J Gastrointest Surg 2007;11:660-665.

2 Macartney-Coxson DP, Hood KA, Shi HJ, et al. Metastatic susceptibility locus, an $8 \mathrm{p}$ hot-spot for tumour progression disrupted in colorectal liver metastases: 13 candidate genes examined at the DNA, mRNA and protein level. BMC Cancer 2008;8:187.

3 Sugai T, Habano W, Nakamura S, et al. Allelic losses of $17 p, 5 q$, and $18 q$ loci in diploid and aneuploid populations of multiploid colorectal carcinomas. Hum Pathol 2000;31:925-930.

4 Zeitoun G, Mourra N, Blanche-Koch H, et al. Genomic profile of colon cancer metastases. Anticancer Res 2008;28:3609-3612.

5 Diep CB, Parada LA, Teixeira MR, et al. Genetic profiling of colorectal cancer liver metastases by combined comparative genomic hybridization and Gbanding analysis. Genes Chromosomes Cancer 2003; 36:189-197.

6 Diep CB, Kleivi K, Ribeiro FR, et al. The order of genetic events associated with colorectal cancer progression inferred from meta-analysis of copy number changes. Genes Chromosomes Cancer 2006;45:31-41.

7 Al Mulla F, Keith WN, Pickford IR, et al. Comparative genomic hybridization analysis of primary colorectal carcinomas and their synchronous metastases. Genes Chromosomes Cancer 1999;24:306-314.

$8 \mathrm{Hu}$ XT, Chen W, Wang D, et al. The proteasome subunit PSMA7 located on the 20q13 amplicon is overexpressed and associated with liver metastasis in colorectal cancer. Oncol Rep 2008;19:441-446.

9 Korn WM, Yasutake T, Kuo WL, et al. Chromosome arm 20q gains and other genomic alterations in colorectal cancer metastatic to liver, as analyzed by comparative genomic hybridization and fluorescence in situ hybridization. Genes Chromosomes Cancer 1999;25:82-90.

10 Tanaka T, Watanabe T, Kazama Y, et al. Chromosome 18q deletion and Smad4 protein inactivation correlate with liver metastasis: A study matched for T- and Nclassification. Br J Cancer 2006;95:1562-1567.

11 Paredes-Zaglul A, Kang JJ, Essig YP, et al. Analysis of colorectal cancer by comparative genomic hybridization: evidence for induction of the metastatic phenotype by loss of tumor suppressor genes. Clin Cancer Res 1998;4:879-886.

12 Blaker H, Graf M, Rieker RJ, et al. Comparison of losses of heterozygosity and replication errors in primary colorectal carcinomas and corresponding liver metastases. J Pathol 1999;188:258-262.

13 Walker BA, Morgan GJ. Use of single nucleotide polymorphism-based mapping arrays to detect copy 
number changes and loss of heterozygosity in multiple myeloma. Clin Lymphoma Myeloma 2006;7:186-191.

14 Camps J, Grade M, Nguyen QT, et al. Chromosomal breakpoints in primary colon cancer cluster at sites of structural variants in the genome. Cancer Res 2008;68:1284-1295.

15 World Health Organization. WHO International Histological Classification of Tumors, Vol 1-25. Geneva, 1967-1981 2nd edn. Springer-Verlag: Berlin, 1988-1992.

16 Greene FL. Current TNM staging of colorectal cancer. Lancet Oncol 2007;8:572-573.

17 Sayagues JM, Abad MM, Barquero H, et al. Intratumoral cytogenetic heterogeneity of sporadic colorectal carcinomas suggests several pathways to liver metastasis. J Pathol 2010;221:308-319.

18 Bengtsson H, Irizarry R, Carvalho B, et al. Estimation and assessment of raw copy numbers at the single locus level. Bioinformatics 2008;24:759-767.

19 Venkatraman ES, Olshen AB. A faster circular binary segmentation algorithm for the analysis of array CGH data. Bioinformatics 2007;23:657-663.

20 Benjamini Y, Hochberg Y. On the adaptive control of the False Discovery Rate in multiple testing with independent statistics. JEBS 2000;25:60-83.

21 Sayagues JM, Fontanillo C, Abad MM, et al. Mapping of genetic abnormalities of primary tumours from metastatic CRC by high-resolution SNP arrays. PLoS ONE 2010;29:e13752.

22 Diep CB, Teixeira MR, Thorstensen L, et al. Genome characteristics of primary carcinomas, local recurrences, carcinomatoses, and liver metastases from colorectal cancer patients. Mol Cancer 2004;3:6.

23 Sheffer M, Bacolod MD, Zuk O, et al. Association of survival and disease progression with chromosomal instability: a genomic exploration of colorectal cancer. Proc Natl Acad Sci USA 2009;106:7131-7136.

24 Rigola MA, Casadevall C, Bernues M, et al. Analysis of kidney tumors by comparative genomic hybridization and conventional cytogenetics. Cancer Genet Cytogenet 2002;137:49-53.

25 De Angelis PM, Clausen OP, Schjolberg A, et al. Chromosomal gains and losses in primary colorectal carcinomas detected by $\mathrm{CGH}$ and their associations with tumour DNA ploidy, genotypes and phenotypes. Br J Cancer 1999;80:526-535.

26 Lassmann S, Weis R, Makowiec F, et al. Array CGH identifies distinct DNA copy number profiles of oncogenes and tumor suppressor genes in chromosomal- and microsatellite-unstable sporadic colorectal carcinomas. J Mol Med 2007;85:293-304.

27 Kanai M, Hamada J, Takada M, et al. Aberrant expressions of HOX genes in colorectal and hepatocellular carcinomas. Oncol Rep 2010;23:843-851.

28 Ma S, Guan XY, Lee TK, et al. Clinicopathological significance of missing in metastasis B expression in hepatocellular carcinoma. Hum Pathol 2007;38: 1201-1206.

29 Fong CW, Chua MS, McKie AB, et al. Sprouty 2, an inhibitor of mitogen-activated protein kinase signaling, is down-regulated in hepatocellular carcinoma. Cancer Res 2006;66:2048-2058.

30 Niu RF, Zhang L, Xi GM, et al. Up-regulation of Twist induces angiogenesis and correlates with metastasis in hepatocellular carcinoma. J Exp Clin Cancer Res 2007;26:385-394.
31 Okada T, Suehiro Y, Ueno K, et al. TWIST1 hypermethylation is observed frequently in colorectal tumors and its overexpression is associated with unfavorable outcomes in patients with colorectal cancer. Genes Chromosomes Cancer 2010;49:452-462.

32 Boissan M, Beurel E, Wendum D, et al. Overexpression of insulin receptor substrate- 2 in human and murine hepatocellular carcinoma. Am J Pathol 2005;167: 869-877.

33 Slattery ML, Samowitz W, Curtin K, et al. Associations among IRS1, IRS2, IGF1, and IGFBP3 genetic polymorphisms and colorectal cancer. Cancer Epidemiol Biomarkers Prev 2004;13:1206-1214.

34 Gutenberg A, Gerdes JS, Jung K, et al. High chromosomal instability in brain metastases of colorectal carcinoma. Cancer Genet Cytogenet 2010;198:47-51.

35 Wei JS, Johansson P, Chen QR, et al. microRNA profiling identifies cancer-specific and prognostic signatures in pediatric malignancies. Clin Cancer Res 2009;15:5560-5568.

36 Chattopadhyay I, Singh A, Phukan R, et al. Genomewide analysis of chromosomal alterations in patients with esophageal squamous cell carcinoma exposed to tobacco and betel quid from high-risk area in India. Mutat Res 2010;696:130-138.

37 Ruano Y, Mollejo M, Ribalta T, et al. Identification of novel candidate target genes in amplicons of Glioblastoma multiforme tumors detected by expression and CGH microarray profiling. Mol Cancer 2006; $5: 39$.

38 Ochiumi T, Tanaka S, Oka S, et al. Clinical significance of angiopoietin-2 expression at the deepest invasive tumor site of advanced colorectal carcinoma. Int J Oncol 2004;24:539-547.

39 Iwamoto $\mathrm{M}$, Banerjee $\mathrm{D}$, Menon LG, et al. Overexpression of E2F-1 in lung and liver metastases of human colon cancer is associated with gene amplification. Cancer Biol Ther 2004;3:395-399.

40 Zhang YL, Pang LQ, Wu Y, et al. Significance of Bcl-xL in human colon carcinoma. World J Gastroenterol 2008;14:3069-3073.

41 Zhao ZR, Zhang ZY, Zhang $\mathrm{H}$, et al. Overexpression of Id-1 protein is a marker in colorectal cancer progression. Oncol Rep 2008;19:419-424.

42 Kim HL, Vander Griend DJ, Yang X, et al. Mitogenactivated protein kinase kinase 4 metastasis suppressor gene expression is inversely related to histological pattern in advancing human prostatic cancers. Cancer Res 2001;61:2833-2837.

43 Yamada SD, Hickson JA, Hrobowski Y, et al. Mitogenactivated protein kinase kinase 4 (MKK4) acts as a metastasis suppressor gene in human ovarian carcinoma. Cancer Res 2002;62:6717-6723.

44 Wang L, Pan Y, Dai JL. Evidence of MKK4 prooncogenic activity in breast and pancreatic tumors. Oncogene 2004;23:5978-5985.

45 Watanabe T, Wu TT, Catalano PJ, et al. Molecular predictors of survival after adjuvant chemotherapy for colon cancer. N Engl J Med 2001;344:1196-1206.

46 Ogino S, Nosho K, Irahara $\mathrm{N}$, et al. Prognostic significance and molecular associations of $18 \mathrm{q}$ loss of heterozygosity: a cohort study of microsatellite stable colorectal cancers. J Clin Oncol 2009;27:4591-4598.

47 Walter A, Houlston R, Tomlinson I. Association between chromosomal instability and prognosis in colorectal cancer: a meta-analysis. Gut 2008;57:941-950. 
48 Baselga J. The EGFR as a target for anticancer therapy-focus on cetuximab. Eur J Cancer 2001;4: S16-S22.

49 Ko MA, Rosario CO, Hudson JW, et al. Plk4 haploinsufficiency causes mitotic infidelity and carcinogenesis. Nat Genet 2005;37:883-888.

50 Wang Y, Liu DP, Chen PP, et al. Involvement of IFN regulatory factor (IRF)-1 and IRF-2 in the formation and progression of human esophageal cancers. Cancer Res 2007;67:2535-2543.

51 Veeck J, Noetzel E, Bektas N, et al. Promoter hypermethylation of the SFRP2 gene is a high-frequent alteration and tumor-specific epigenetic marker in human breast cancer. Mol Cancer 2008;7:83.

52 Karoui M, Tresallet C, Julie C, et al. Loss of heterozygosity on $10 \mathrm{q}$ and mutational status of PTEN and
BMPR1A in colorectal primary tumours and metastases. Br J Cancer 2004;90:1230-1234.

53 Berghella AM, Contasta I, Pellegrini P, et al. Peripheral blood immunological parameters for use as markers of pre-invasive to invasive colorectal cancer. Cancer Biother Radiopharm 2002;17:43-50.

54 Bessard A, Sole V, Bouchaud G, et al. High antitumor activity of RLI, an interleukin-15 (IL-15)-IL-15 receptor alpha fusion protein, in metastatic melanoma and colorectal cancer. Mol Cancer Ther 2009;8:2736-2745.

55 Ried T, Just KE, Holtgreve-Grez H, et al. Comparative genomic hybridization of formalin-fixed, paraffinembedded breast tumors reveals different patterns of chromosomal gains and losses in fibroadenomas and diploid and aneuploid carcinomas. Cancer Res 1995; 55:5415-5423.

Supplementary Information accompanies the paper on Modern Pathology website (http://www.nature.com/ modpathol) 